\title{
Diagnosis of Pulmonary Tuberculosis by Score System in Children and Adolescents: A Trial in a Reference Center in Bahia, Brazil
}

\author{
Clemax Couto Sant'Anna', \\ Marilene Augusta R. C. Santos ${ }^{2}$ \\ and Rosana Franco ${ }^{3}$
}

\author{
Martagão Gesteira Puericulture and Pediatrics Institute of the \\ Federal University of Rio de Janeiro and Department of \\ Pediatrics of the Medicine School of Federal University of Rio \\ de Janeiro ${ }^{1}$, Pediatrics Society of the State of Rio de Janeiro \\ $(\text { SOPERJ })^{2}$, Rio de Janeiro, RJ; Otávio Mangabeira Specialized \\ Hospital (HEOM) $)^{3}$ Salvador, BA, Brazil
}

\begin{abstract}
Since 2002, the Brazilian Ministry of Health has recommended a score system for tuberculosis diagnosis of children and adolescents that does not need bacteriological positivity, because most cases in this age group have few bacteria. An observational, transversal study was carried out at the outpatient health care service of the reference medical service in Salvador, Bahia, including 164 patients with pulmonary tuberculosis, with ages ranging between 1 and 15 years of age, who were treated from 1990 to 2001 . The gold standard used to establish the diagnosis was clinical, radiological, epidemiological and based on follow-up data. The score system for diagnosis purposes was tested retrospectively. The median age and the average age of the 164 patients were 6 and 6.62 years (SD \pm 4.33 ), respectively. About $65 \%$ of the sample reported a history of close contact with a tuberculous adult. The BCG vaccine coverage was $70.7 \%(116 / 164)$. It was found that $26 \%(43 /$ 164) of the patients had severe malnutrition. Out of this group, $26 / 43(60.47 \%)$ were $<5 \mathrm{~mm}$ reactive to the tuberculin test. On the other hand, out of the 91 patients with tuberculin test $<5 \mathrm{~mm}$, $29 \%(26 / 91)$ had severe malnutrition. The use of the score gave the following distribution: a) TB very likely in $81.7 \%(134 / 164)$ of the patients; b) possible TB in 15.9\% (26/164) and TB unlikely in $2.4 \%$ (4/164). Among patients who had been vaccinated more than 2 years before, there was a 9 times higher risk of finding a tuberculin test above $10 \mathrm{~mm}$ in individuals with probable TB in comparison with the patients with possible or unlikely $\mathbf{T B}$.
\end{abstract}

Key Words: Pulmonary tuberculosis, diagnosis, child. adolescents.

The burden of tuberculosis (TB) in childhood throughout the world is still not well known. Estimates of the World Health Organization consider that every year there are 1.2 million cases and 450,000 deaths of children. The lack of knowledge about this problem is due to many factors, such as difficulty in bacteriological diagnosis, little emphasis on public policies to prevent the disease and a lack of standardized diagnosis criteria

Received on 17 January 2004; revised 12 May 2004.

Address for correspondence: Dr. Clemax Couto Sant'Anna. R.Barão de Mesquita 459 A bloco 2 ap. 102- Tijuca, Rio de Janeiro, RJ, Brazil, Zip code: 20540-001. Phone: 12- 25904640; 2571-0752; fax:25904891.E-mail: clemax@vetor.com.br

The Brazilian Journal of Infectious Diseases 2004;8(4):305-310 (C) 2004 by The Brazilian Journal of Infectious Diseases and Contexto Publishing. All rights reserved.
$[1,2]$. That is why the diagnostic score systems for TB in childhood published in the literature since the 1950's show a great diversity of criteria, sensitivity and specificity. This may be due to the variety of presentations of $\mathrm{TB}$, depending on its prevalence in the different regions of the world. On top of that, few systems have been tested, which limits the broad use of this diagnostic tool [2].

Since 2002, the Brazilian Ministry of Health (Ministério da Saúde - MS) officially recommends a score system to diagnose pulmonary TB in childhood and in adolescents [3]. This score system has already been tested in a control case study, in which the TB gold standard was bacteriological evidence. The study revealed $88.9 \%$ sensitivity and $86.5 \%$ specificity [4]. We assessed the same score system, not restricted to 
the cases that were positive to bacteriology, but rather based on the diagnostic standards used in practice in a reference public tuberculosis health service, as most of the cases of TB in childhood are abacillary $[1,4]$.

\section{Materials and Methods}

We made an observational, descriptive and transversal study based on the analysis of 164 clinical records of children and adolescents between 1 and 15 years of age, who were later treated for pulmonary tuberculosis at the outpatient health care service of Childhood Pulmonology of the Octávio Mangabeira Specialized Hospital (HEOM), during the period from January 1990 to November 2001. The HEOM treats several different respiratory diseases of patients who mainly live in and come from Salvador and part of the interior of the state of Bahia.

The patients who fulfilled at least 3 of the criteria below and presented a clinical-radiological response favorable to antituberculosis treatment after 30 days were considered as TB cases.

- History of contact with people with TB during the previous 2 years.

- Compatible clinical condition: fever, cough and slow development of weight loss or that had not responded to the use of antibiotics.

- Tuberculin test above $10 \mathrm{~mm}$ in subjects not vaccinated with BCG or vaccinated more than 2 years before and, above $15 \mathrm{~mm}$ in subjects vaccinated less than 2 years before.

- Thoracic X-ray with images suggesting primary or post-primary TB: hilum or paratracheal adenomegalies, slowly developing pneumonia, diffuse micronodular infiltrate, lung infiltrates in the superior third of the lung cavities and bronchial dissemination.

Patients whose medical records were incomplete were excluded. Clinical, radiological and demographical variables were studied, as well as the interpretation of the tuberculin test with PPD, Rt 23UT in conformity with the official standards of the Ministry of Health [3].

All patients underwent a posteriori assessment using the score system recommended by the Ministry of Health [3] (Table 1). Thus 3 criteria of diagnostic classification were used, depending on the total score.

- TB very likely: above 35 points.

- Possible TB: between 30 and 25 points.

- TB unlikely: below 25 points.

Then the variables were described with their corresponding frequency distribution for the categories and the central tendency and dispersion measures for the continuous variables, as well as the calculation of the odds ratio (OR) and the corresponding 95\% confidence interval (CI).

The data were analyzed and processed using the Statistical Package for Social Sciences application [5]. This research is in conformity with the Code of Medical Ethics of 1988 (articles 122 and 130) and Resolution 196/96 of the National Council of Health and complementary legislation.

\section{Results}

\section{General description}

One hundred sixty-four children and adolescents, 82 females and 82 males composed the sample. Patients coming from the city of Salvador corresponded to $83 \%$ $(136 / 164)$ of the sample. The other people came from other cities. The median age and the average age of the 164 patients were 6 and 6.62 years of age $(S D \pm 4.33)$, respectively. The minimum age was 1 year and the maximum 15 years of age. In $88 \%(144 / 164)$ of the patients there were TB suggestive symptoms, such as: fever or cough, adynamia, expectoration, weight loss or sweating that had been lasting for more than 2 weeks. Five patients presented associated extrapulmonary TB. Nearly $100 \%$ (163/164) of the cases showed thoracic $\mathrm{X}$-rays compatible with TB, except for one patient with endobronchial TB with a normal X-ray. About 63\% (107/ 
164) of the sample reported a history of close contact with a tuberculous adult. Of this group 31/107 (29\%) had not received the $\mathrm{BCG}$ vaccine. Vaccine coverage with BCG was $70.7 \%$ (116/164). It was observed that $83 \%(96 / 116)$ of the patients had been vaccinated with BCG more than 2 years before, and 74\% (71/96) of them were $10 \mathrm{~mm}$ or more reactive to the tuberculin test. In about $17 \%$ (20/116) of the vaccinated children, BCG had been given at least 2 years before, and in 95\% (19/ 20) of them, the reaction was $<5 \mathrm{~mm}$.

It was found that $26 \%(43 / 164)$ of the patients had severe malnutrition [6]. Of this group, 26/43 (61\%) were $<5 \mathrm{~mm}$ reactive to the tuberculin test. On the other hand, $28.6 \%$ (26/91) of the 91 patients with $<5 \mathrm{~mm}$ on the tuberculin test had severe malnutrition.

\section{Description in conformity with the score system}

The use of the score system showed the following distribution: a) very likely TB in $82 \%$ (134/164) of the patients; b) possible TB in $16 \%$ (26/164) and unlikely $\mathrm{TB}$ in $2.4 \%$ (4/164).

Figure 1 shows the main variables of the very likely TB subgroup. The group vaccinated with BCG and with a score above 35 corresponded to $68 \%$ (91/134).

Among those who had a score above 35 , there was a predominance of subjects who were $<5 \mathrm{~mm}$ reactive to the tuberculin test, which was equivalent to $48 \%$ $(64 / 134)$. It was found that $35 \%(47 / 134)$ were $\geq 15 \mathrm{~mm}$ reactive subjects and $16 \%(22 / 134)$ were reactive between 5 and $9 \mathrm{~mm}$.

Table 2 shows the OR comparing the most common variables in the subgroup of patients with very likely TB, described in Figure 1, for the subgroup of patients with possible/unlikely TB. The variables were: age equal to or less than 6 years of age, tuberculin test above 10 $\mathrm{mm}$ among the subjects vaccinated more than 2 years before, history of close contact with a tuberculous individual, presence of TB suggestive symptoms, evidence of radiological alterations and malnutrition in the subgroup of patients.

The subgroup of very likely TB patients presented variables associated with high risk of developing the disease, such as: age equal to or below 6 years of age OR $=9.55$ (CI 2.59-41.64), tuberculin test above $10 \mathrm{~mm}$ among the subjects vaccinated more than 2 years before $\mathrm{OR}=2.63$ (CI 1.13-6.14) and a history of close contact with a tuberculous individual OR = 19.12 (CI 5.76-70.07).

\section{Discussion}

The current role of the Salvador TB reference public hospital is to provide health care services to TB cases in children and adolescents of up to 15 years of age, referred from the public health care network of the city of Salvador and its outskirts. It does not necessarily mean that only the most severe cases are concentrated in that sample, nevertheless these are the cases that for different reasons have managed to get treatment at this service.

The state of Bahia still has a high TB incidence, as it is a part of the Northeastern region of Brazil, which has the second highest TB incidence rate in the country $[7,8]$.

Our data do not show a significant difference as regards gender, similar to the evidence published in several surveys, showing that TB inchildhood does not predominate among males as much as it does in young adults [8].

As soon as the system was designed we were interested in retrospectively testing the score system for TB diagnosis recommended by the Ministry of Health. However, at that time the TB Standards had not yet been published [3]. Thus, it is important to document the results of the scores found in the TB cases that were accepted as such by this health care service, which is acknowledged by the academy and by society. At the same time we carried out another study at the university hospital of Rio de Janeiro. It was a control case study, with the same score system, in which the cases were bacteriologicaly tested and which showed sensitivity and specificity above $85 \%$ for TB diagnosis [4]. The state of Rio de Janeiro has the highest TB incidence coefficient in Brazil [8].

Clinical and radiological aspects contained in the score presented a high prevalence of diagnosis, with TB suggestive symptoms in $88 \%$ of the cases and with radiological findings in nearly $100 \%$ of them. We can suppose that such findings shall reach or exceed the prevalence values under normal conditions of use in 
Figure 1. Clinical, roentgenological and epidemiological features in very likely TB patients (> 35 points)

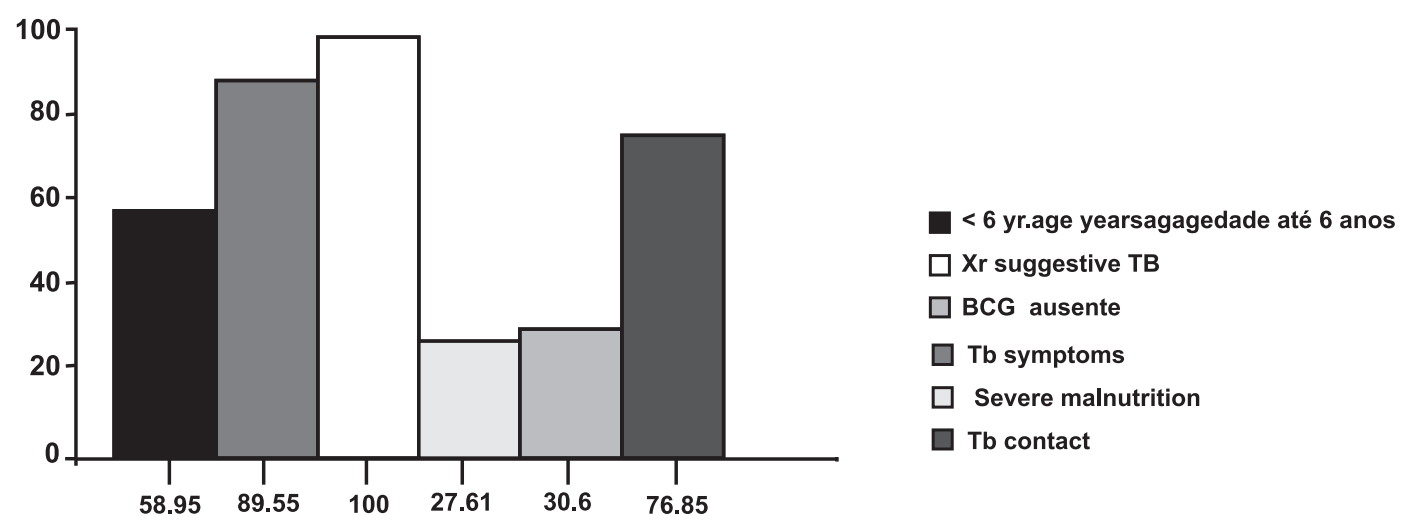

Table 1. Score system for diagnosis of pulmonary tuberculosis (PTB) in children. Ministry of Health, Brazil

\section{Clinical manifestations}

Fever or cough, lost energy, sputum, weight loss, night sweats $>2$ weeks

No symptoms or symptoms $<2$ weeks

Respiratory infection improving with or without antibiotic therapy for common bacteria
Score

$+15$

0

$-10$

$+15$

$+15$

$+5$

$-5$

$+10$

0

None or occasional

BCG vaccination and Tuberculin test

$B C G \geq 2$ years or no $B C G(\geq 10 \mathrm{~m})$

$+15$

$\mathrm{BCG}<2$ years $(\geq 15 \mathrm{~mm})$

$+15$

BCG yes $/$ no (5mm to $9 \mathrm{~mm})$

$+5$

BCG yes/no $(\leq 5 \mathrm{~mm})$

\section{Nutritional status}

Severe malnutrition (grade III)

Eutrophic or no severe malnutrition 
Table 2. Comparison between patients with very likely TB and possible/unlikely TB in relation to: a tuberculin test above $10 \mathrm{~mm}$ in patients vaccinated more than 2 years before, age $\leq 6$ years, history of close contact with a tuberculous individual, presence of TB suggestive symptoms, evidence of radiological alteration, and malnutrition.

\begin{tabular}{|c|c|c|c|}
\hline & $\begin{array}{c}\text { Very likely } \mathbf{T B} \\
\mathrm{N}=134\end{array}$ & $\begin{array}{c}\text { Possible/ unlikely TB } \\
\text { N=30 }\end{array}$ & $\begin{array}{c}\text { OR } \\
(95 \% \mathrm{CI})\end{array}$ \\
\hline $\begin{array}{l}\text { PPD above } 10 \mathrm{~mm} \\
\text { (vaccination more than } \\
2 \text { years before) }\end{array}$ & 69 & 3 & $\begin{array}{c}9.55 \\
(2.59-41.64)\end{array}$ \\
\hline Age $\leq 6$ years & 79 & 10 & $\begin{array}{c}2.63 \\
(1.13-6.14)\end{array}$ \\
\hline $\begin{array}{l}\text { History of close contact } \\
\text { with a tuberculous individual }\end{array}$ & 100 & 4 & $\begin{array}{c}19.12 \\
(5.76-70.07)\end{array}$ \\
\hline $\begin{array}{l}\text { Presence of TB suggestive } \\
\text { symptoms }\end{array}$ & 120 & 24 & $\begin{array}{c}2.14 \\
(0.75-13.6)\end{array}$ \\
\hline $\begin{array}{l}\text { Evidence of radiological } \\
\text { alteration }\end{array}$ & 134 & 29 & $\begin{array}{c}0.18 \\
(0.13-0.28)\end{array}$ \\
\hline Malnutrition & 97 & 24 & $\begin{array}{c}0.66 \\
(0.25-1.73)\end{array}$ \\
\hline
\end{tabular}

the health care services of the public network, which is the target population towards which the system is geared, because this study was developed at the outpatient health care service of a public hospital that is a reference center and thus is responsible for treating the most complex cases referred by experts for the purpose of defining a diagnosis.

Two thirds of the sample reported having had contact with tuberculous adults, thus reflecting the importance of researching this piece of data for childhood TB diagnosis $[1,7,9]$. Nevertheless, we found evidence of another aspect of the problem, which is the fact that in $30 \%$ of the cases of children under 15 years of age, the reference of an index-case, usually an adult, had not been obtained. We must remember that, on the other hand, many children are the TB index-case in some families. This forces the doctor who establishes the diagnosis of a case of TB in a child to guide the family and help them look for other people that are in contact with them and who could have TB, yet they ignore this fact [9]. It's been observed that there is a 19 times higher risk for those with a history of close contact with a tuberculous adult, which emphasizes how important it is to obtain this piece of data in any suspicious case of child or adolescent TB.

In our study, $70 \%$ of the patients had been vaccinated with BCG. The efficacy and effectiveness of BCG immunization in childhood has been widely discussed, although there is a consensus that this vaccine can protect against severe forms of tuberculosis, in spite of the fact that there is little efficacy for pulmonary TB [1]. In our case series studies, such as this one, in which TB patients are assessed, we cannot measure the vaccine protection provided by BCG. This would demand another study design.

The literature shows that the post-vaccine tuberculin reaction tends to become less intense with time. That is why children vaccinated with BCG at birth, although they 
remain immune for many years, experience a reduction of the size of the tuberculin test, unless they have had new natural infections of $M$. tuberculosis. These new infections by the wild bacillus would produce more intense and lasting reactions than does BCG. The diagnostic score system adopts a two-year period after BCG vaccination to interpret the tuberculin test, based on the literature [3,10]. However, severe TB cases, which are often associated with severe malnutrition, can show a non-reactive tuberculin test, because these are anergising conditions for the patient [10]. Possibly, this explains the fact the $29 \%$ of the cases were non-reactive to the tuberculin test among patients who had been vaccinated against TB with BCG. Although our study showed evidence of this phenomenon, we emphasize that $95 \%$ of the children and adolescents with TB and who had been vaccinated more than 2 years before had a non-reactive tuberculin test, thus indicating the occurrence of severe forms of the disease. Among the patients vaccinated more than 2 years before, a 9 times higher risk of finding a tuberculin test above $10 \mathrm{~mm}$ was found in individuals very likely to have $\mathrm{TB}$, compared to patients with possible or unlikely TB.

The tuberculin test that been regarded as of little value for subjects previously vaccinated with BCG under the previous official standards of the Ministry of Health has been revalued recently; this provoked its inclusion as a useful element for diagnosis and for decision making regarding the beginning of chemoprophylaxis in children [3].

The finding of $26 \%$ cases with severe malnutrition may reflect several circumstances: the poor life conditions of this part of the population, which resorted to the hospital, the extremely severe stage of TB of these patients and the long period of disease development that had passed since the initial symptoms, before the final diagnosis, which brought about progressive malnutrition, which had been slowly consuming them [10]. In our study, there was no evidence that led us to attribute this result to any of these specific causes.

The possible limitations of studying TB cases that have not been bacteriologicaly proven, and therefore without having used the unquestionable gold standard, reveal how difficult it is to study this disease in childhood. TB is pauci-bacillary in children, that is, it develops with few bacilli and, on top of that, it is difficult to obtain material for the sputum test, because of the natural difficulty of patients to expectorate. That is why most papers about this topic, such as this one, are based on clinical-radiological and epidemiological data to diagnose TB in childhood [1].

The retrospective assessment of the score system that we studied has shown its use as an auxiliary element in diagnosing childhood TB at the reference outpatient health care service of a city in which TB is still a large burden [8].

\section{References}

1. Starke, Jr. Pediatric tuberculosis: time for a new approach. Tuberculosis 2003;83:208-12.

2. Hesseling A.C., Schaaf H.S., Gie R.P., et al. A critical review of diagnostic approaches used in the diagnosis of childhood tuberculosis. Intl J Tuberc Lung Dis 2002;6:1038-45.

3. Brasil. Ministério da Saúde. Fundação Nacional de Saúde. Tuberculose: guia de vigilância epidemiológica. Brasília, DF. 2002, 98 p.

4. Sant'Anna C.C., Orfaliais C.T.S., March M.F.B.P. A retrospective evaluation of a score system adopted by the Ministry of Health, Brazil, in the diagnosis of pulmonary tuberculosis in childhood: a case control study. Rev Inst Med trop S. Paulo 2003;45:103-5.

5. SPSS. Statistical Package for the Social Sciences. Release 10.0 for Windows. 2000. Chicago, IL, USA.

6. NCHS. Growth curves for children, birth-18 years. Dept of Health Education and Welfare Publication $\mathrm{n}^{0}$ (PHS)78-1650. Washington: DC.:National Center for Health Statistics, 1977.

7. Franco R, Santana MA, Matos E, Sousa V, Lemos ACM. Clinical and radiological analysis of children and adolescents with tuberculosis in Bahia, Brazil. Braz J Infect Dis 2003; 7:73-81.

8. Hijjar M.A., Oliveira M.J.P.R., Teixeira G.M. A tuberculose no Brasil e no mundo. Bol. Pneumol Sanit 2001;9: 9-16.

9. Caldeira Z.M.R, Sant'Anna C.C., Aidé M.A. Tuberculosis contact tracing among children and adolescents. Rev Saude Publica 2004;38.

10. Sarinho E.S., Reis F.J.C., Barbosa V.C.N.M. Teste tuberculínico. In: Sant'Anna CC (ed). Tuberculose na infância e na adolescência. Rio de Janeiro, Atheneu, 2002;p:43-50. 